\title{
COMPARATIVE ANALYSIS OF THE LEADERSHIP STYLE OF THE BULGARIAN CADETS - PART IN THE NATIONAL SECURITY EDUCATION
}

\author{
Nevena ATANASOVA - KRASTEVA \\ "Vasil Levski” National Military University, Veliko Tarnovo, Bulgaria \\ nevena_atanasova@abv.bg
}

\begin{abstract}
As part of the cadets' tactical leadership training research of the leadership skills of the cadets at Vasil Levski National Military University, Bulgaria was carried out. The current paper presents the results of the analysis of the professional and social components of the leadership style of Bulgarian cadets. The results could be used for the improvement of the future skills of national security experts. The situational leadership theory is used as the basis for the developing of a model for building the cadet's leadership skills.
\end{abstract}

Keywords: national security, leadership training, model

About 2000 years ago when Confucius was asked by the Emperor what was necessary for a state to be strong and prosperous, he answered: "There are 3 elements essential in the matters of the State, Food, Military equipment, and Confidence of the people in the ruler. " [2]

\section{Introduction}

The popular use of the term "security" in today's dynamic world stems from the fact that security is perceived as a fundamental concept in the theories of social relations. Numerous definitions of its meaning, summarized and analyzed by security systems researcher Professor Semerdjiev, conclude that "security is a basic necessity of the state and other subjects of social life; purpose of the State's activity; a state of no threat to the fundamental values of the state and the nation; an opportunity for a nation (society, person) to protect their values from any threat." [3]

The scope of security and the levels of its functioning give a clear picture of the different types of security and their relationship. These levels are as follows: [4]

- Level 1: security of individuals;

- Level 2: security of groups;

- Level 3: security of a state;
- Level 4: security of a community (of states);

- Level 5: security of the world (the planet). According to the author, the first three levels of security - of the individual, the group, the state can be united under the concept of "national security", and the last three levels - of the state, the community, the world - are referred to as international security.

Ever since the first use of the term "national security" in 1904 by US President Theodore Roosevelt and its first definition proposed by the American philosopher and publicist Walter Lipman in 1943 to date, a number of authors and scientists have considered this concept a category, status, process, result, etc. In today's scientific and public space, there are abundant studies, visions, and analyses related to security in its diverse types, forms, classifications and manifestations. 
It is difficult to state just the definition of the essence of national security because of the universality of this category, which also requires universal tools in defining its content. The most common is the understanding of national security as a dynamic state, which is associated with the lack of direct danger to the state, the society and the individual from armed operations, from political or economic threats. [3]

In this respect, guaranteeing the national security as a state of protection of the constitutional state system, the just enforcement of the laws of the country, the free functioning of all forms of power and the inviolability of life, the name and honor of each person are the primary responsibility of each state and its leaders.

The training of national security experts is an extremely popular professional field in which many higher education institutions offer educational services. A number of political, military and public leaders expand their competences through training in bachelor and master degree programs in national security.

For this reason, the mission of the National Military University is to build the future officers morally, mentally and physically, to form individuals and leaders with leadership skills capable of managing public and special structures in peacetime and crises, and of participating in national and multinational projects to maintain security, peacekeeping projects and community development projects. [5]

\section{Research and results}

The training of the cadets - future experts in national security, the so called tactical training, includes academic, military, leadership, foreign language and physical training. The subject Leadership Training is organized in a modular principle. Leadership as a basic term in organizational practice and in the theory of social governance is seen as a mechanism for impacting people in order to achieve a common goal through joint action. In this line of thought, the training of cadets as future commanders with leadership qualities is also a major challenge and a challenge for the academic staff and for the command of the University.

Forming the cadets as professionals in the respective military specialty along with their training in leadership and obtaining practical experience is a long and complicated educational process. This dayto-day responsibility lies with the military instructors and all the company and platoon commanders. The progress in the development of each cadet is monitored every year during the complex tactical sessions and exercises, where skills to work at a tactical level are demonstrated i.e. how learners perform leadership tasks and have direct contact with their subordinates (cadets from lower years) and how they perform the assigned tasks.

In order to test the leadership skills of the cadets, P. Hursi and K. Blanchard base the developed model for leadership building of the trainees adopted at the National Military University of Veliko Turnovo on the theory of situational leadership. [1] The model offers criteria for assessing the two aspects of leadership development of the cadets social and professional aspect, which have been the subject of a long-term research by the author of this report since 2012. Every year, military instructors assess the professional performance of the cadets from the different training courses according to the following criteria: dynamics; eagerness; decision-making; taking responsibility; communication skills; discipline; readiness. The platoon and company commanders, on their part, provide assessments of the social elements of the leadership behavior of the learners during the exercises, which are: performance; emotional sustainability; intellectual potential (analytical thinking); striving for improvement; culture of speech; understanding of duty; display of honor and dignity.

The evaluation of these indicators of the professional and social aspect of the cadets' 
leadership behavior is carried out according to the six-point system, as the scores between 5 and 6 regarding the expression of each item under study are viewed as the desired final ones.

This report presents the results of the analysis of the social and professional component of the cadets' leadership style indicators received during the complex practical exercise Tactical Survival in 2017. The study includes 42 cadets from all training courses - military specializations Mechanized and Tank Troops, Intelligence, Military Police and Signal Intelligence and Electronic Warfare. It should be noted that these specializations belong both to the
Military Affairs and National Security professional fields, as the cadets, apart from the military professional qualification, also receive civilian professional qualification of Expert in National and Regional Security.

The aim of the study is to check the level of the trainees' leadership skills, to analyze the results and to propose further work for the military personnel subject to the educational and training process. Figure 1 presents the data from the overall average assessments of the professional aspect of the leadership style behavior of all the cadets who have taken part in the study according to their year of training.

Figure 1: Average values of the cadets' professional leadership final grades - all courses (years of training

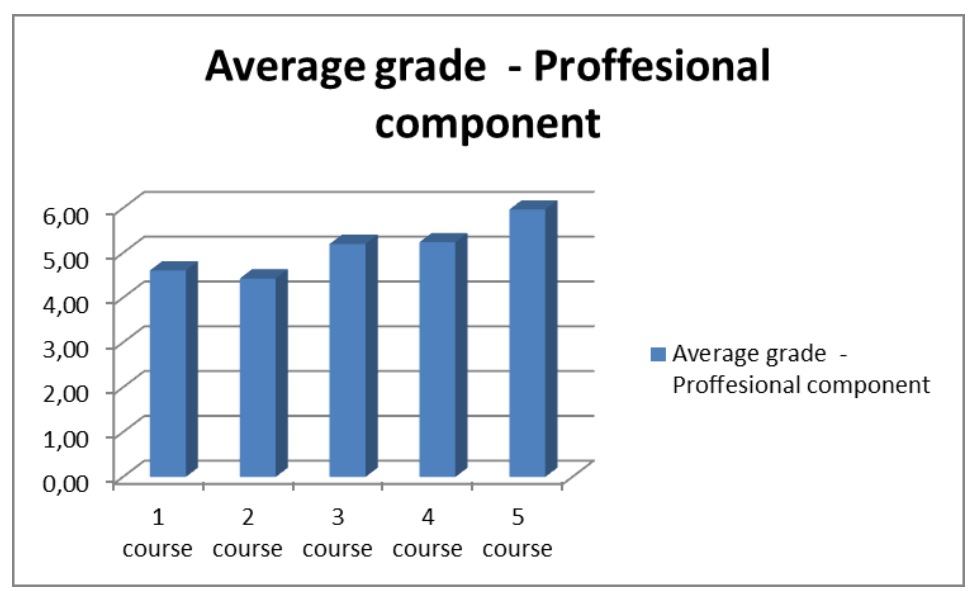

The data shows the high ratings of military instructors for the professional performance of the cadets from higher courses. Estimates between 5 and 6 as a desirable final score of the demonstration of adequate leadership performance during the exercise demonstrate the understanding and application of the theoretical knowledge in a real situation, and the making of appropriate decisions for their subordinates on the team they lead. At the same time, the lower scores of the first, second, and thirdyear cadets are expected and logical in view of their little experience and limited opportunities to take part in the management and decision-making processes. These results prove the gradual development of leadership skills in the learners as a consequence of the natural course of professional military training. For this purpose, Leadership Modules include consistent upgrading and complicating of theoretical preparation, and practical upgrade of case studies and work in the field.

The results obtained should not reassure military specialists, but on the contrary, they should look into the detailed analysis of the assessments of each batch of cadets with the idea of timely correction or change in the teaching methods, opportunities to influence and motivate for learning, update the tasks for the practical classes.

For example, the figures shown in Figure 2 
and referring to the benchmarking of each occupational performance indicator of leadership behavior of second-year cadets show lower values. Impression makes the low value of the "responsibility" criterion, which may be the result of the lack of responsibility in the activity of some learners, the impossibility or the unwillingness to complete the given tasks, or the misunderstanding of the consequences of failure of the instructions given. These analyses would help the academic staff to properly select how to work with cadet trainees, as well as to constantly seek feedback in order to build a sense of belonging to the team and concerns about the security of each team member.

\section{Figure 2: Average values of the II year cadets' components of professional leadership style}

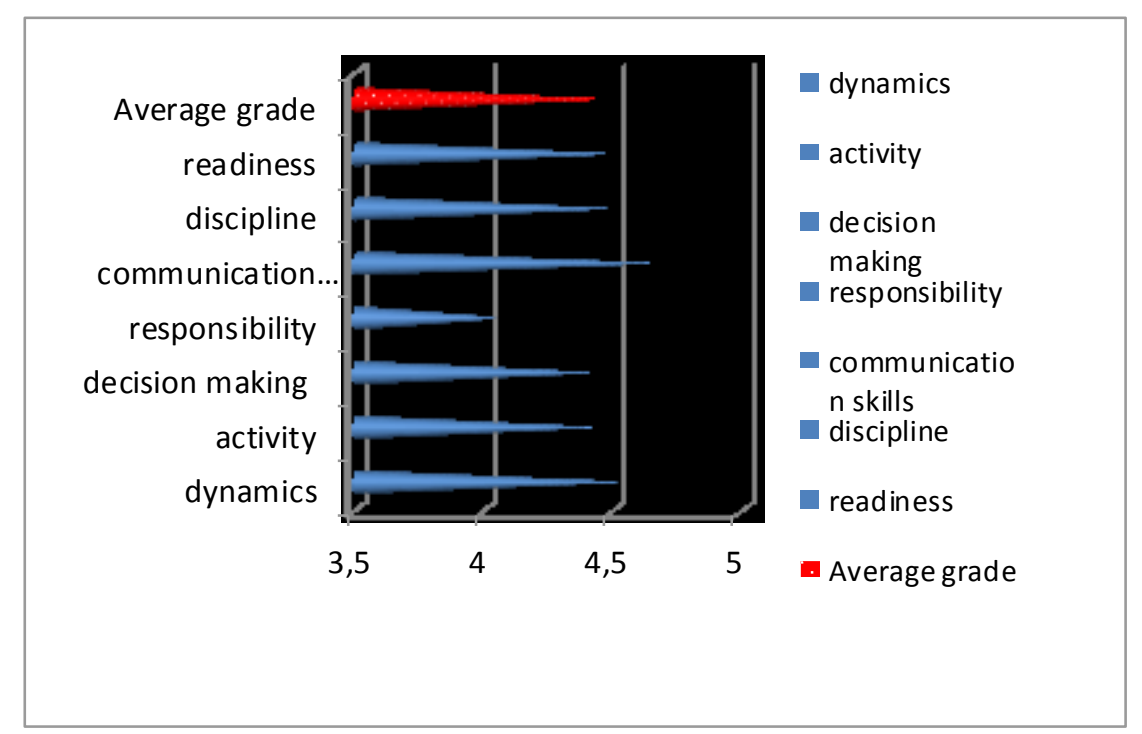

The results of the indicators of the social aspect of the cadets' leadership style performance are presented in Figure 3 and are analogous to the professional aspects. The building of social skills in the behavior of the young people - trainees at the Military University is a process that should not be considered a constant. Moreover, the analysis of the social elements in the cadets' leadership style in accordance with the developed model can reveal the essence and development of such dynamic constructs of each learner's mental activity, such as motivation, the level of commitment and personal conviction regarding the ability to handle each situation. [1]

Evaluations given by platoon and company commanders to their subordinates reveal various levels as compared to the desired end state, namely, according to the results obtained at the end of the training course at the Military University, the graduates may be expected to possess a various knowledge - professional and general, to have mastered specific skills, to demonstrate established values and relationships, to share a desire for development of one's own personality. For most commanders, this conclusion would be evidence of the greater responsibility and direct involvement of the command staff in the education process. At the same time, it should be noted that since the study involves a representative sample of each university course, and that each commander and instructor prefers to appoint in leadership positions during real teaching the best and most capable trainees 
and to delegate rights to them, this suggests that the above results cannot be related to all the students from the different batches. In this respect, the role of the educational effects of the direct commanders increases, together with the adoption of an individual approach by them, as well as the demand for feedback from the subordinates and maintaining of an adequate communicative strategy.

Figure 3: Average values of the cadets' social leadership final grades - all courses (all years of training)

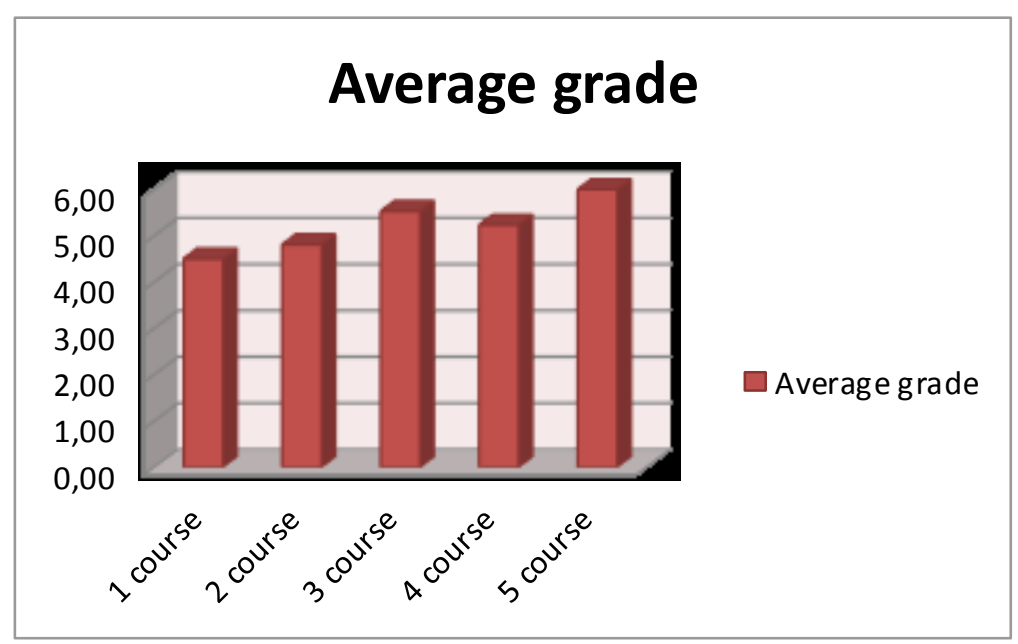

The not very large number of trainees at the Vasil Levski Military University should be encouraged and supported in the process of their social development and forming as personalities. This implies flexibility in organizing their military duties and caring for each individual cadet. In the different years of training, the young people face a variety of issues that are also significant factors in their future individual development. These conclusions are supported by the assessments made by the commanders on the individual indicators of the social aspect of the leadership behavior of their subordinates during the exercise.

Figure 4 shows the results obtained by generalizing the second-year cadets' scores of the individual indicators of the social component of their leadership performance. It is normal, given their younger age as compared to their senior colleagues, to see lower values, which can be explained by the lack of rich experience in social situations. A closer look at the individual criteria also reveals the problem areas that may be used by their commanders for their future work. Namely, the fact that modern young people have difficulty in oral communication, they find it hard to present themselves or do not yet understand their place in the Army institution and do not feel involved in the organization's activities.

Such peculiarities in the development and formation of young people as future professionals are expected in relation to the information society in which we live, the widespread use of technology in all areas of modern life, and the constant changes in our environment - external and internal. This is what requires increased attention to the training of the cadets and continuous work with each subordinate on the part of the commanders. These assessments may also signal faults or lack of competencies to select the right tools that would influence, motivate an immature person to direct their attention to building socially responsible behavior. 
Figure 4: Average values of the II-year cadets' components of social leadership style

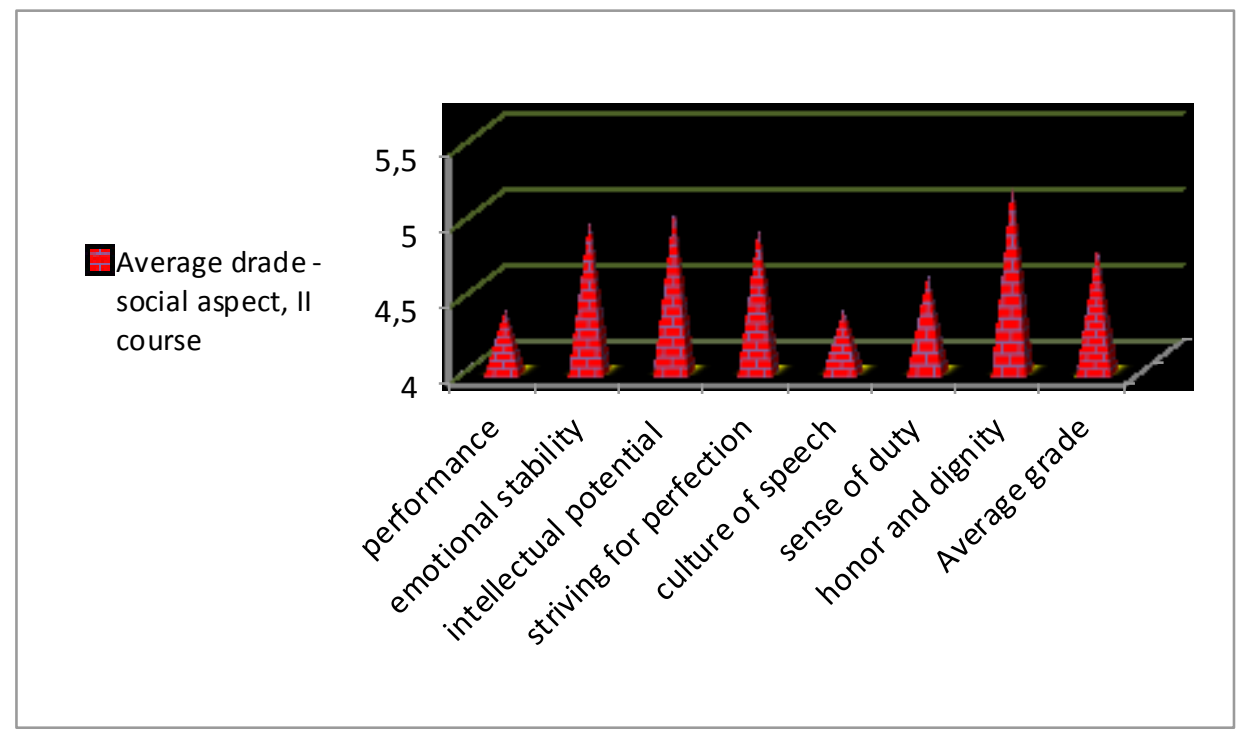

It can be summed up that all efforts of direct commanders and instructors can be successful and at graduation of the military educational institution only high levels of social values and professional competencies be reported only when all participants in this process consciously and constantly work as a team in one direction, towards one goal - building leaders and experts, guarantees of the security of the state, society and personality.

\section{Conclusions}

The analysis and comparison of the research results of the aspects of the different cadets' leadership style confirmed some preliminary expectations, along with the defining of problematic areas and weaknesses in the process of leadership forming of future officers and security experts. This data can assist those responsible for the educational process in establishing specific measures and new practices in the important task of preparing capable and knowledgeable cadre for the sphere of national security. The changing security environment, the new threats and risks require a new type of "human resource", trained and skilled, with a built-in value system and effective models for leadership behavior. The high quality of the educational service in the professional field of national security can be achieved only by properly selecting the learners, motivated and highly trained academic staff and commanders, modern facilities and experienced command. Only raised standards in the training and the link with practitioners and stakeholders will contribute to the training of qualified staff for the needs of the national security

\section{References}

[1] Atanasova - Krasteva N., Leadership building of cadets, Veliko Tarnovo, 2012

[2] Semerdjiev Tsv., Strategic leadership and leadership. Leader., Softrade, Sofia., 2007

[3] Semerdjiev Tsv., Theoretical foundations of national security, http://semerdjiev.com/wpcontent/uploads/2014/10/01

[4] Slatinski N., Security dimensions, Publ. house "Pradigma",Sofia, 2000

[5] Vasil Levski NMU, www.nvu.bg 